\title{
Methodology for Testing of a Drive System with Remote Monitoring and Control
}

V. Dimitrov

Key Words: Remote monitoring and control; intelligent energy meter; asynchronous drive; soft starter; programmable logic controller PLC.

Abstract. A laboratory drive system with remote monitoring and control has been designed and built. An asynchronous motor controlled by a soft starter and remote monitoring and control by contemporary devices has been provided. This laboratory system is used for research and in teaching. In this paper, methodology of tests is developed. Some examinations are presented. Thus an experimental verification of the developed methodology is carried out. Systems for remote monitoring and control on energy consumption, efficiency and proper operation of the controlled objects are very often used in different spheres of industry, building automation, transport, electricity distribution network, etc. The optimal solution for each particular case could be achieved but a complex research and testing have to be previously performed using the developed methodology.

\section{Introduction}

The speed regulation of the asynchronous motors in many fields of industry is not necessary. Many drives need to be started and stopped smoothly but its speed has to be constant through the operating modes: conveyors and conveyor belts, pumps, fans, compressors, automatic doors, small cranes, belt-drive machines, etc. Soft starters can be used in those cases - their implementation enhances the starting performance of asynchronous drives by allowing the motor to start gradually and smoothly in a controlled manner [1-9]. The contemporary soft starters can be set up to the requirements of the individual application and the motor is adjusted to the machine's load behaviour.

Therefore, the study and examination of the soft starters is very important. A laboratory system has been designed and built and remote monitoring and control by an intelligent energy meter and PLC has been provided [10]. Methodology of examinations has been developed and verified.

\section{Methodology of Testing and Examinations}

In this article, a methodology of examination of the influence of the acceleration time on the drive performance is presented. It allows determining the dependencies between energetic parameters of the drive (power factor, efficiency, THD, etc.) and different settings of the soft starter:

(1) $\cos \varphi=f\left(t_{a c c} ; t_{d c c} ; U_{i n}\right), \eta=f\left(t_{a c c} ; t_{d c c} ; U_{i n}\right)$;
(2) $T H D_{I}=f\left(t_{a c c} ; t_{d c c} ; U_{i n}\right)$;

(3) $T H D_{U}=f\left(t_{a c c} ; t_{d c c} ; U_{i n}\right)$.

Capturing the dynamic characteristics at drive starting is also described

$I=f(t), P=f(t), Q=f(t), U=f(t), \cos \varphi=f(t)$,

(4) $T H D_{I}=f(t), T H D_{U}=f(t)$.

The energy meter Sentron PAC3200 and it opportunity for storing (memorizing) the maximum reached values of the parameters is used [11].

\subsection{Methodology of Examination of the Influence of the Acceleration Time on the Starting Current}

The algorithm of the examination is as follows:

1) Laboratory system must be switched on by the breaker $A F$. Three phase voltage is displayed on the Sentron PAC3200. Many other parameters could be visualized by pressing F2 or F3 function keys [11].

2) Direction of the motor rotation has to be selected (by F or R buttons).

3) The time $t_{\text {acc }}$ has to be set by the potentiometer. The time $t_{d c c}$ and the initial voltage $U_{i n}$ can also be set by other potentiometers. The Boost-function could also be activated by the switch on the Touch Panel.

4) Sentron PAC3200 has to be set to display the currents. Min./Max. values stored in the memory can be checked using F1 function key and they have to be cleared by pressing the F3 key.

5) The drive starts by pressing the button on the Touch Panel. The values of the currents have to be observed. If there are voltmeters connected between the soft starter and drive, the values of the three phase motor voltage could also be observed. Acceleration time can be measured by a chronometer. The yellow indicator of the soft starter lights up after $10 \mathrm{~s}-$ the motor has received maximum power supply (figure 1).

6) Maximum reached currents during stating can be displayed using F1 function key. They have to be written in a table.

7) The drive can be stopped by pressing the button on the Touch Panel. After the soft starter is switched off the drive could be stopped by the button $B r$ if it is necessary.

8) The time $t_{\text {acc }}$ has to be changed and tests 3 ) - 7) have to be performed again.

9) The average values of the starting current at different settings have to be calculated and graphs can be plotted. 
The dependencies of the other parameters $(P, Q, \cos \varphi$, $T H D$, etc.) can be captured by similar methods.

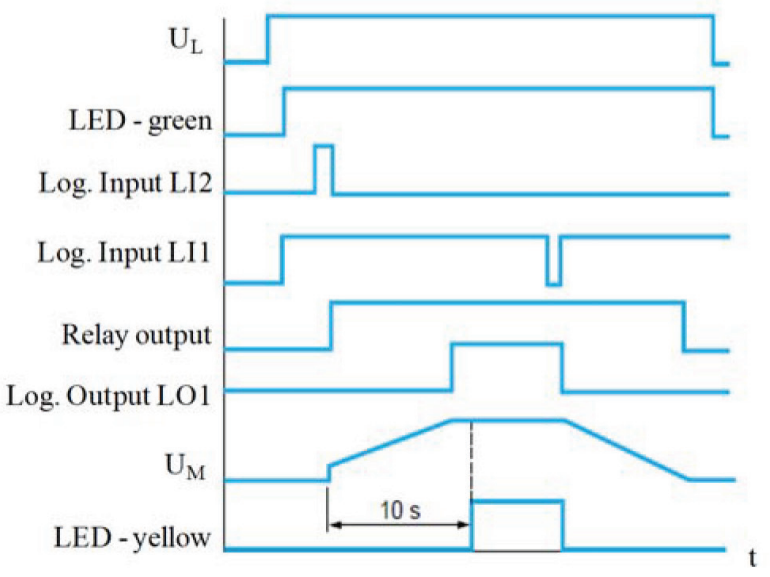

Figure 1. Soft starter inputs and outputs and indicator readings at three-wire control

\subsection{Remote Monitoring and Analyzing the Electrical System's Parameters}

The device Sentron PAC3200 has to be connected to the PC and the software Powerconfig V3.7 must be run [12]. This software package is a combined service and commissioning tool for communication-capable measuring devices from the Sentron family. The parameters of the drive can be displayed on the PC monitor and the measured values can be watched in real time in numerical and graphic type in standardized views (selecting by the menu). The date, time and value of the selected parameters are displayed in real time. The refresh time could be changed (minimum value is $330 \mathrm{~ms}$ ) and the differences could be watched. The moment values are written and graphics can be plotted. Read-out and saving of message lists, load profiles, and histories is also possible.

The variation of the motor currents during different regimes is shown in the figure 2.

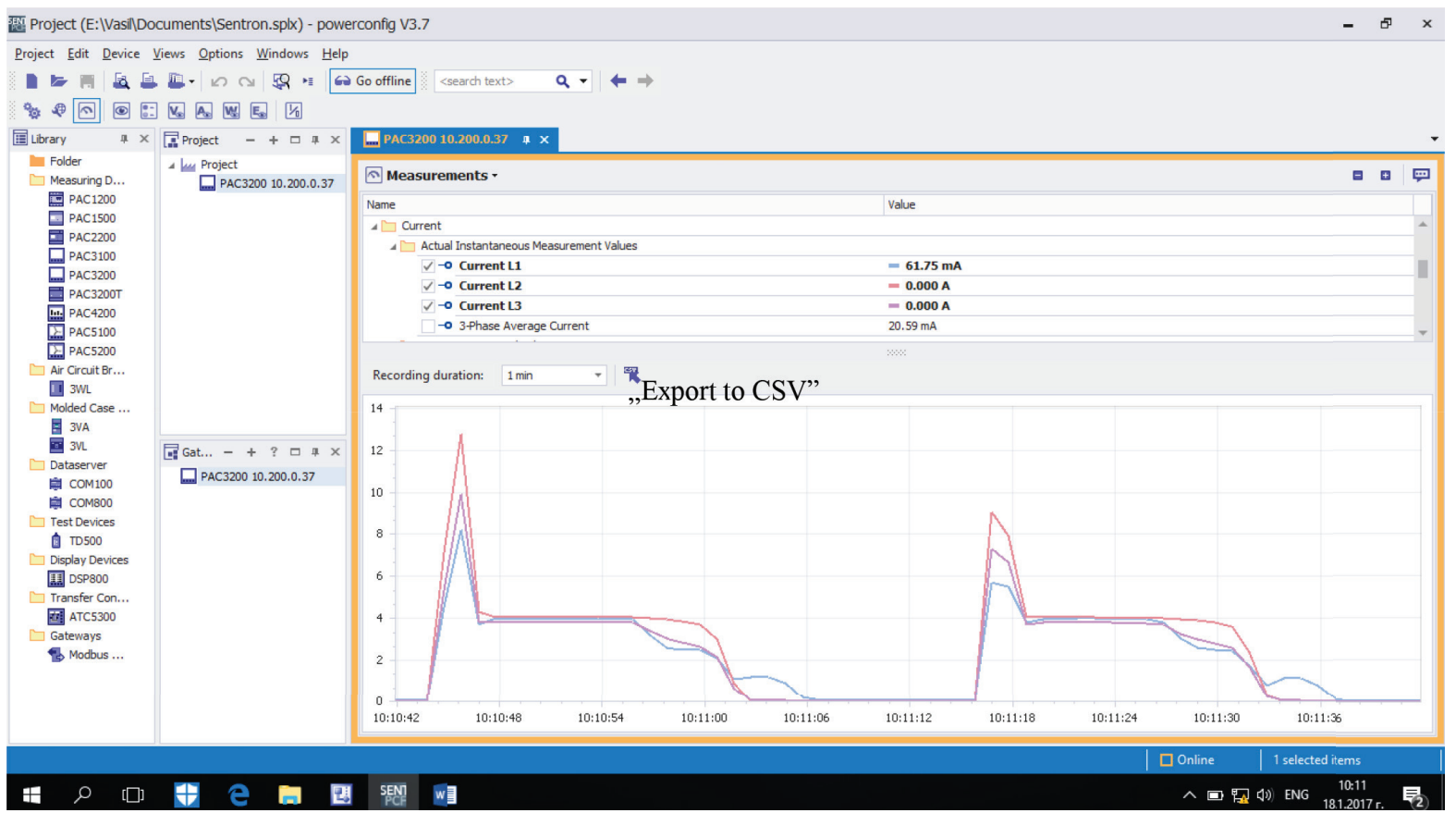

Figure 2. Software Powerconfig V3.7 - current monitoring

The big values of the starting currents are clearly visible. The currents are constant during the steady-state operation and decrease slowly after the Stop command. Two tests were made at different values of the acceleration time. The software Powerconfig V3.7 provides the opportunity to export data to Excel tables using the "Export to CSV" button. The duration of recording has to be defined in advance. The data can be processed in Excel and many graphics can be plotted and analyzed.

\section{Results of Testing and Examinations}

Many tests have been performed using the developed methods. The captured dynamic characteristics $I=f(t)$ are shown in figure 3. The data have been previously exported to an Excel table and these graphs were plotted. The increased value $(\sim 1 A)$ of the current I1 after Stop command is caused by affecting the electrodynamic brake.

The correlation between the acceleration time and starting current at different settings of the initial voltage is shown in the figure 4.

It is clearly visible that the change of the acceleration time setting, respectively the rate of the supply voltage increasing, results in a different maximum reached value of the starting current. With the acceleration time is increased, the starting current is smaller, and when the initial value of the supply voltage is increased, starting current also increases. 


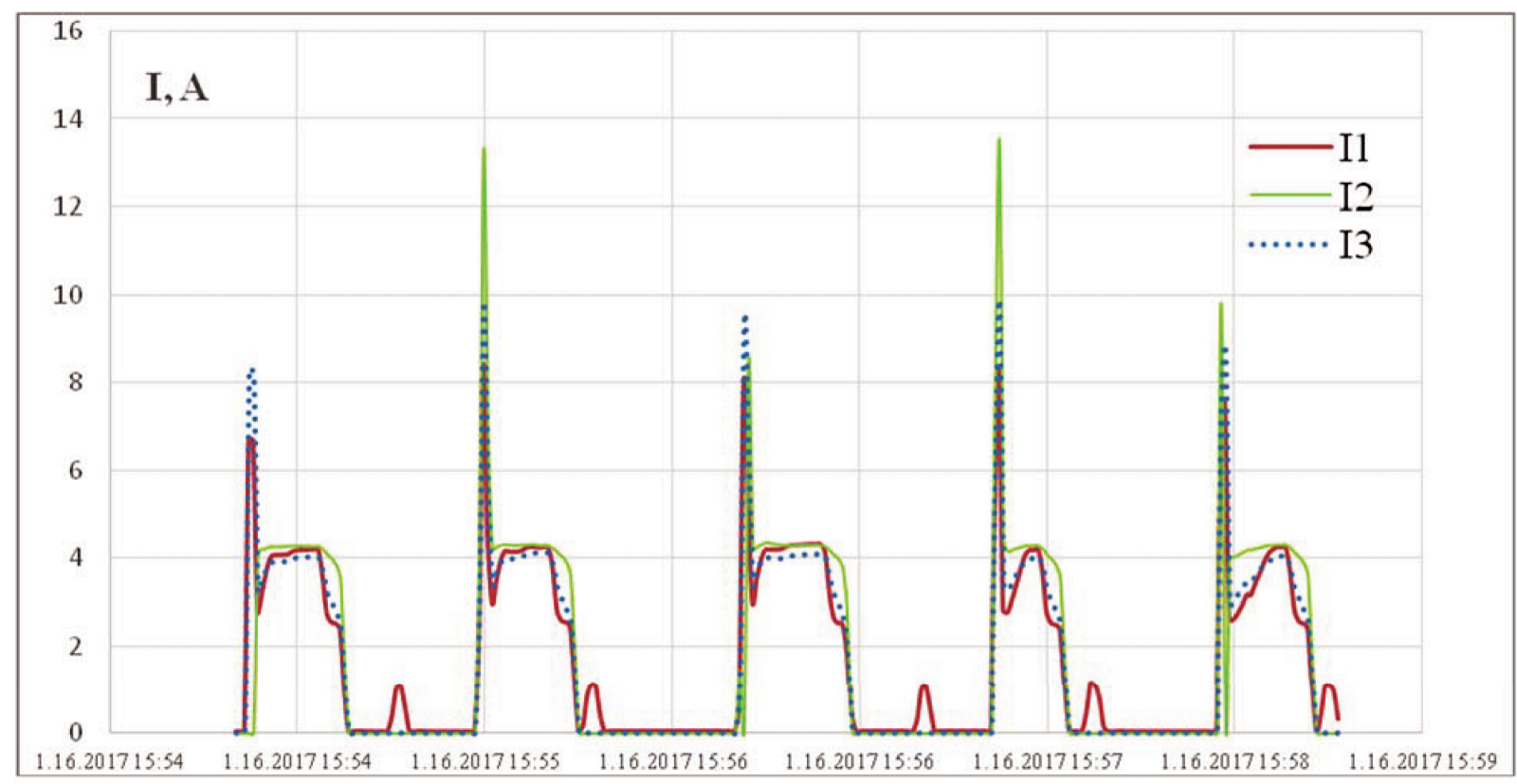

Figure 3. Drive current at different settings of the acceleration time $t_{\text {acc }}$ and initial voltage $U_{\text {in }}$

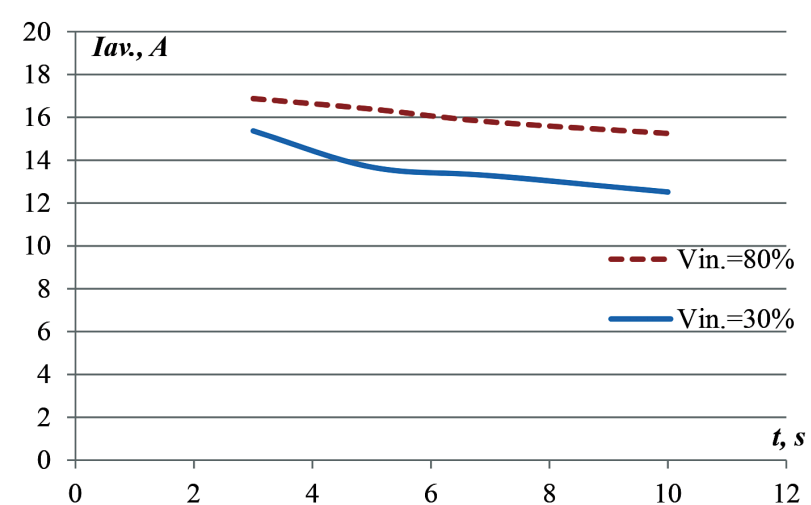

Figure 4. Impact of the acceleration time $t_{\text {acc }}$ and initial voltage $\mathrm{U}_{\text {in }}$ on the starting current

Similarly, the correlation between the acceleration time and the power factor has been taken and the graphs have been plotted (figure 5). It can be seen that the power factor is improving by reducing the acceleration time. This dependency can be explained by the bigger starting torque developed by the motor for a short time, and hence the greater value of the active power.

The correlation between the acceleration time and the coefficient THD-I is shown in figure 6. The THD-I value deteriorates as the acceleration time increases. This dependency can be explained by the operation of the thyristor voltage regulator. Longer acceleration time is provided by increasing the unlocking angle $\alpha$ of the thyristors, which leads to a distortion of the sinusoidal form of the current $[1,2]$.

Therefore, changing the settings has a different influence on the drive parameters. The optimal solution for each particular case could be achieved but a complex research and testing have to be previously performed.

Following the described methodology, studies at different loads can be carried out and a family of characteristics can be obtained.
Similar tests can be conducted to determine the effect of the Boost function and the deceleration time on the drive performance and energy efficiency.

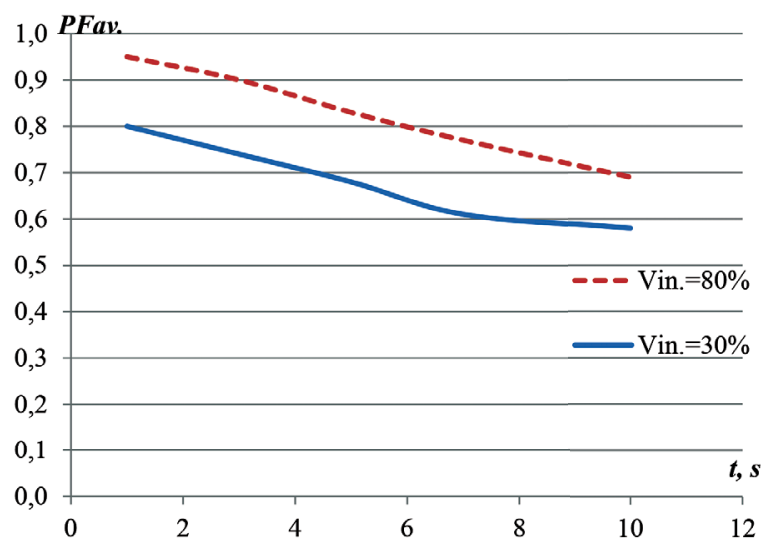

Figure 5. Impact of the acceleration time $\mathrm{t}_{\text {acc }}$ and initial voltage $\mathrm{U}_{\text {in }}$ on the power factor during starting

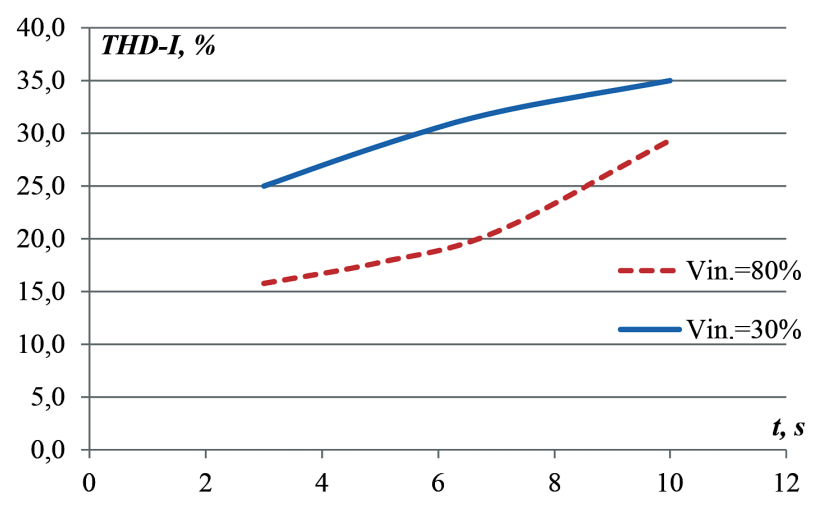

Figure 6. Impact of the acceleration time $t_{\text {acc }}$ and initial voltage $\mathrm{U}_{\text {in }}$ on the THD-I during starting 


\section{Conclusion}

The fast industrial progress and development of electrical drives and control systems set up higher requirements to research and education quality. Training the skills for involving, programming, and setting-up and testing of contemporary control devices and measuring equipment is very important. Knowledge of the relevant software products is necessary. This is why a laboratory system has been designed and built using contemporary devices. An asynchronous motor is controlled by a soft starter and opportunities for remote monitoring (by an intelligent energy meter) and control (by a PLC and Touch panel) have been provided. Soft starters are widely used in industry, building automation and transport for control on asynchronous drives in many typical applications - pumps, fans, compressor, conveyors and other belt systems, automatic doors, small cranes, etc. Intelligent measuring devices are always implemented as primary components in the contemporary systems for remote monitoring of the power supply and proper operation of the controlled objects. PLCs are also very often used in different types of control system configurations.

This laboratory system offers various possibilities of research and implementation into practice many laboratory exercises. Methodologies for different tests and examinations are developed. The influence of soft starter settings on the drive performance and energetic parameters amendment are examined and presented in the paper. The correlations obtained during the experiments are similar to the characteristics known in the technical literature [1-5]. Thus an experimental verification of the described methods has been carried out.

\section{Manuscript received on 07.07.2017}

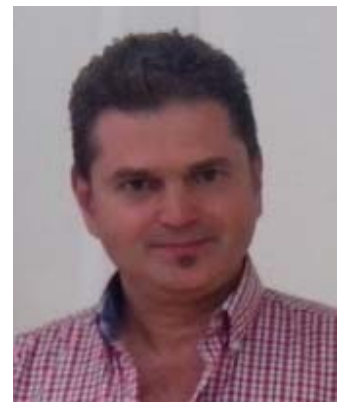

Vasil Dimitrov received his engineering M.Sc. degree in Automation of Electrical Drives in June 1991 from the Technical University of Sofia. He received a Ph.D. degree in May 2013 from Todor Kableshkov University of Transport - Sofia. In October 2014 he became Assoc. Prof. at Todor Kableshkov University of Transport - Sofia, Faculty of Telecommunications and Electrical Equipment in Transport. His research interests are in field of contemporary systems for control on electrical drives in transport and industry, including adaptive control on asynchronous drives, as well as of SCADA systems for remote control of dispersed objects in different sectors of the economy.

Contacts:

Todor Kableshkov University of Transport Department of Power Engineering and Electrical Equipment in Transport

158 Geo Milev St., 1754 Sofia, Bulgaria e-mail:vdimitroff@abv.bg

\section{References}

1. Hughes, A. Electric Motors and Drives - Fundamentals, Types and Applications. Third Edition, Elsevier Ltd., 2006.

2. Bakshi, U. A., M. V. Bakshi. Electrical Drives and Control. Technical Publications Pune, India, 2009.

3. Boldea, I. S., A. Nasar. Electrical Drives. NY, CRC/Taylor \& Francis Group, 2006.

4. De, N. K., P. K. Sen. Electric Drives. Prentice Hall of India, 2006.

5. Stouffer, K., V. Pillitteri, S. Lightman, M. Abrams, A. Hahn. Guide to Industrial Control Systems (ICS) Security. NIST Special Publication 800-82, USA, 2015.

6. The Essential Guide of Automation \& Control. Schneider Electric, 2012.

7. Soft Starts for Single-Phase and Three-Phase Asynchronous Motors. Catalog, Schneider Electric, 2011.

8. Soft Starters Altistart 01 for Asynchronous Motors. Catalog, Schneider Electric, 2014.

9. Dimitrova, E. A. Building Automation and Control Systems. Academic Journal Mechanics, Transport, Communications, 14, 2016, 3/2, Art. ID 1395, XI-26-XI-31, ISSN 1312-3823.

10. Dimitrov, V. Design and Setting up of a Laboratory Drive System with Remote Monitoring and Control. - Information Technologies and Control, 2017, No. 2, 25-30.

11. SENTRON PAC3200. Technical Specification. Siemens, 2011. 12. http://w3.siemens.com/powerdistribution/global/en/lv/portfolio/pages/powerconfig.aspx. 